\title{
Exploring the Potential of Bacterial Cellulose for Use in Apparel
}

\author{
Jennifer Harmon*, Logan Fairbourn and Natalie Thibault \\ University of Wyoming, USA
}

*Corresponding author: Jennifer Harmon, Assistant Professor, Department of Family and Consumer Sciences, University of Wyoming, USA.

Received Date: April 04, 2020

Published Date: April 16, 2020

\section{Abstract}

As consumers continue to shift towards being more environmentally conscious, new materials are emerging on the industry landscape. Bacterial cellulose applications are of particular interest. This unique material has the potential to yield more sustainably produced cellulose than traditional products. To this point, investigation into common, essential properties for apparel applications has been limited. This project compared 3 main types of media, 2 variations of these media types, 2 drying methods and 1 treatment application to ascertain the most economical and beneficial methods of cultivation for this material. The resulting material was measured for cellulose yield, strength, and elongation and abrasion resistance. Overall, it was discovered that material grown in the molasses mannitol media produced the most cellulose. The strongest cellulose was also molasses mannitol and the most resistant to abrasion. Cellulose from the treatment conditions tended to have the greatest length for elongation at the breaking point. Overcoming some of this material's deficits will be necessary in order for it to become a more widely used source of cellulose in apparel.

Keywords: Bacterial cellulose; Yield, uniformity; Strength; Abrasion resistance; Absorbency

Abbreviations: BC- Bacterial Cellulose; HS- Hestrin Schramm; HSM- Hestrin Schramm Mannitol; MS- Molasses; MSM- Molasses Mannitol; HFCSHigh Fructose Corn Syrup; HFCSM- High Fructose Corn Syrup Mannitol

\section{Introduction}

Disposable clothing, the mode of apparel production and consumption in recent decades has increasingly emphasized "fast fashion." Contributing to this fast fashion orientation is globalization, which has drastically lowered the cost of clothing production, resulting in prices so low that consumers may now consider clothes disposable [1]. Additionally, consumers' now desire new clothing more often, leading to so called "season less" seasons [2]. The fast fashion process leaves an environmental impact through waste at nearly every stage of the product use cycle.

One consequence of the fast fashion system is increasing amounts of textile waste. According to the Environmental Protection Agency, the main source of textiles in municipal waste is discarded clothing [3]. Further, since 1960, acceleration in textile waste generation can be observed through the over 8 times increase in the amount of tons discarded [3]. Additional textile waste is produced during manufacturing, particularly in the cutting stage. Textile waste from this stage in apparel production can exceed $16 \%$
[4]. An additional 6 plus percent of waste products from textiles and sewing threads can be observed in the sewing process [4].

Cellulose derived waste tends to decompose more quickly than its synthetic counterparts. Cellulose is the most freely available and inexpensive carbohydrate polymer in the world [5]. It is typically derived from plants and plant wastes for fibres like cotton, linen, rayon, and more [5]. Cotton, the most popular cellulosic fibre, is one of the most commonly used raw fibre materials [6]. In fact, 17 million bales of cotton were produced in the U.S. in 2012 [7]. Cotton has numerous positive attributes which make it ideal for apparel, including the potential for flexibility and softness, moisture absorption, breathability, and moderate strength [8].

Nonetheless, cotton fibre manufacturing requires large amounts of land, water, and pesticide resources each year, making cotton less than ideal from a sustainability perspective. Cotton is a water intensive crop, requiring at least 20 inches of rainfall each year for optimal growth [9]. In countries with low annual rainfall, irrigation 
is necessary to cultivate this crop. Excessive irrigation often leads to land degradation. Although cotton has a small share of overall agricultural land at $2.4 \%$, cotton cultivation accounts for $24 \%$ of insecticide and $11 \%$ of pesticides sales annually [10]. Cotton, a seed fibre, while a highly pure form of cellulose, still has impurities such as pectin and plant particulate which must be removed with additional water and chemicals. Other stem based cellulosic fibres, like flax and hemp; have to undergo further processing to remove impurities such as lignin and hemicellulose.

In addition to being more resource-intensive to cultivate, cotton garments contribute to significant waste in modern landfills. In 2014, landfills received 10.4 million tons of textile waste, roughly the total weight of two dozen modern skyscrapers [11]. The main source of this textile municipal solid waste is discarded clothing [11]. One positive aspect of cotton textile waste, and indeed all cellulosic textile waste, is that cellulose is biodegradable. Certain fabric treatments can accelerate or reduce cotton's ability to degrade but cotton will still degrade more completely than other commonly used synthetic fibres, such as polyester [12].

Interest in reducing the environmental impacts of the textile and apparel industry is growing. Recently, textile research investigated methods aimed at replacing cotton as the primary source of cellulose in textile products [13]. One avenue being increasingly explored to reduce the environmental impact of the industry is the use of biotechnology in producing cellulose [14]. In addition to the wood pulp based fibres, bacterial cellulose (BC) has been investigated as a potential source of cellulose. In addition to traditional plant sources, cellulose is also produced by several strains of bacteria $[15,16]$. Bacterial Cellulose (BC), is a material produced without the impurities present in plant derived cellulosic products, such as lignin and hemi-cellulose [17]. Lacking hemicellulose and lignin, the cellulose micro fibrils interact extensively with one another via hydrogen bonds. Indeed, these interactions make for a highly crystalline, absorbent, and strong fibre-web [18].

In order for this material to be used in apparel, the potential cellulose yield, as well as basic textile properties, needs to be better established. This study investigated the use of low cost nutrient sources for the cellulose producing bacteria such as high fructose corn syrup and molasses. Additionally, the impact of air and freeze drying methods on BC's textile properties was tested. Finally, the use of a plasticizing glycerol soak was examined for its impact on the material's properties. Impact was assessed in terms of grams per litre of cellulose produced in each media, strength testing, and elongation and abrasion resistance [19].

\section{Literature Review}

As the textile industry engages in increasingly unstable practices to meet rising demand, consumer textile waste and pollution rest among the top concerns in the industry. The year 2017 signified a tipping point for this industry when the EPA reported that textile waste accounted for $8 \%$ of all municipal solid waste [20]. In the wake of this report, the textile industry and its consumers are attempting to identify alternative, eco-friendly textile solutions. One such textile alternative is bacterial cellulose, a material produced by widely present microscopic organisms, which holds promise due to its relative inertness, and sustainable production. Particularly exciting about this material is that bacterial cellulose requires little arable land, no pesticides, and far less water during the course of production due to the static fermentation setup typically employed. A high degree of polymerization and crystallinity, high purity, extremely high absorption and excellent biodegradability that is not restricted by extensive processing common for other cellulose materials further give this material broad potential appeal [21,22].

Bacterial cellulose, while still a cellulosic material, is easily dichotomized from traditional cellulosic textile materials by means of its macromolecular structure, nonwoven nature, and production methods. During the course of fermentation, Acetobacter sps. Produce and extrude pure microcrystalline cellulose fibrils via their trans membrane cellulose synthase enzyme that aggregate into a nonwoven cellulose network supported through both hydrogen bonds between the 3' and 5' hydroxyl groups of the glucose subunits and Van Der Waals interactions [23,24]. This nonwoven cellulose network, Bacterial Cellulose (BC), is ultimately comprised of highly crystalline regions interspersed with amorphous segments [23,24].

Since the discovery of bacterial cellulose, a number of cellulose-extruding microorganisms, namely gram-negative rods of the acetic acid family, have been identified. While many bacteria extrude cellulosic fibres in their formation of biofilms, research tends to focus on Acetobacter xylinum, a bacterium isolated from fruit, first shown to produce cellulose in 1886 and formerly named Gluconacetobacter xylinus [25,26]. The focus on Acetobacter xylinum is due, primarily, to the bacterium's high yield of cellulose relative to other cellulose secreting microorganism at a total of $1 \%-4 \% \mathrm{~W} / \mathrm{V}$ of fermentation media $[27,28]$. This cellulose production efficiency ultimately became of great importance in commercial fermentation operations such as in the production of the Filipino dessert "Nata de Coco." [29].

With organism-specific production capacity understood, inquiries into nutritional requirements as well as the influence of the cellulose production as a function of the growth medium became commonplace; these assessments and new synthetic media often expanded on the work of Hestrin \& Schramm, who typified what is now considered the standard synthetic medium for culturing Acetobacter xylinum [30]. Building on this, it was quickly discovered that the carbon source utilized for the growth of Acetobacter sps. Profoundly impacted the degree of crystallinity of the resultant bacterial cellulose [31]. This offered the potential for bacterial cellulose sheets specialized for their end use in industry because the degree of crystallinity is a critical fibre property that further determines other properties such as tensile strength and, elongation, etc. [32]. Nonetheless, the traditional synthetic media for producing bacterial cellulose requires several expensive components such as pure glucose sugars and peptone [33]. In order to achieve a cost-effective material, low-cost media for bacterial 
cellulose are being explored. Previous research has successfully investigated the use of molasses to replace more expensive carbon sources [34].

Irrespective of the medium used, bacterial cellulose can be produced in a variety of fermentation environments including static, agitated, and stirred cultures [5]. When comparing the fermentation methods, it was noted that agitation increases cellulose yields significantly and decreases production time by up to $90 \%$. At the same time, agitation was discovered to result in irregularly formed cellulose with reduced strength compared to static-fermented cellulose [5]. Furthermore, agitated cultures are known to result in an increased frequency of cellulose negative mutants, which gives rise to the possibility of reduced yields by a culture over time. The uniformity of the BC pellicle is important for appropriateness of the $\mathrm{BC}$ in its end use. For this reason, biomedical and cosmeceutical end uses typically employ static cultivation.

With the basic nutritional requirements understood and the various effects of the fermentation environment understood uncovered, the focus is now largely on the impact of these variables on physical and mechanical properties of the resultant bacterial cellulose. Estimating the strength of the individual micro fibrils is difficult due to the web-like structure the material grows in [21]. Various methods of estimation have determined that the Young's modulus (an indicator of strength under elastic strain) of individual bacterial cellulose fibrils ranges between 78 and 114 GPa [35]. Interestingly, these values are below those often found for cellulose I [35]. On the other hand, the Young's modulus of bacterial cellulose films has been estimated between 15.1 and $18.1 \mathrm{GPa}$, which illustrates bacterial cellulose's lack of elasticity as a fiberweb. The tensile strength of the material, or the maximum stress the material can withstand, is an important predictor of the material's potential as a textile. Little information is available on the tensile strength of individual bacterial cellulose fibrils; however, the tensile strength of bacterial cellulose films has been demonstrated at up to 256 mega Pascal (MPa) under a variety of conditions, making the material comparable to certain common fabrics [21].

To gain further insight into the potential success of $\mathrm{BC}$ as an eco-friendly textile alternative, standard wear tests are needed to determine end uses. Testing methodology for abrasion resistance mimics the general wear of a garment with regards to friction and pressure during use. Abrasion testing includes the weight loss method and the two yarns breakage method [36]. The amount of pressure used on the testing material depends on the end use for such materials; $9 \mathrm{kPa}$ is used for apparel testing and $12 \mathrm{kPa}$ for upholstery, as per ASTM 4966. For the weight loss method, the tested material is run for 5,000 abrasion cycles and weighed for fibre loss [36]. The two yarns breakage method consists of determining the amount of cycles a material can withstand before structural degradation occurs. Structural degradation is ascertained by yarn and fibre breakage such as a tear or hole. Apparel should withstand 5,000 cycles at $9 \mathrm{kPa}$ with minimal pilling and weight loss to be of standard quality per ASTM 4966.
BC naturally occurs in the form of a hydrogel, which proves it to be extremely hydrophilic; however, in order for it to be used as an apparel product BC must be dried after cultivation. Drying methods are especially important in determining end uses for BC due to their effect on this material's morphology, porosity, and mechanical strength [37]. A typical approach to drying BC textiles is through forced heat/oven drying or room temperature air drying. In past research, these drying methods have proven to destroy the original porous microstructure of the hydrogel [37]. In contrast, freeze drying BC removes the water using sublimation, which doesn't affect the morphology or porosity due to surface tension [9]. Room temperature drying methods had minimal effects on fibre diameter, but has shown a decrease in crystallinity [38]. Crystallinity is advantageous for a strong textile, which is another factor when considering end uses for this material. Crystallinity was highest in oven dried samples followed by freeze dried and fibre diameter was greater in freeze dried BC compared to oven drying methods [37]. The decrease in fibre diameter due to heat drying was partially caused by compression during the evaporation process as well as increased hydrogen bonding [37]. From these recent discoveries, drying methods involving $\mathrm{BC}$ are proving to be a crucial step in confirming its end uses and potential in the textile industry.

Given the potential of bacterial cellulose to become a more sustainable source for cellulose in apparel, we sought to discover whether an acceptable yield of BC could be achieved with media made of lower cost ingredients such as molasses and high fructose corn syrup that would make bacterial cellulose a more economically viable solution. Because current data supports the idea that production methods, drying processes, and finishing techniques also impact the physical and mechanical properties of the material, we explored the impact that those cost-conscious media would have on the material's durability properties. Similarly, we investigated how bacterial cellulose produced from these new media would be impacted by drying methods in order to discover the true potential of bacterial cellulose as an eco-friendly, costeffective textile alternative.

\section{Methodology}

\section{Material cultivation}

A freeze-dried monoculture of A. xylium (ATCC 10245) was rehydrated using sterile, deionized water. Immediately after rehydration, the bacterial stock was transferred to HestrinSchramm agar plates in order to expand the culture. The culture was propagated for 8 days at 30 degrees Celsius until visible growth had occurred on the plates. The resulting bacterial growth was then stripped from the agar plates and transferred into test tubes of the sterilized ATCC recommended growing solution for this strain. This bacterium was then propagated for 1 week before being transferred to larger growing containers for an additional week. The bacterial broth was evenly distributed into containers of different media.

Simultaneously, fermentation vessels measuring 14 by 8 by $47 / 8$ inches were filled with $1250 \mathrm{ml}$ of one of six different 
varieties of media (Hestrin-Schramm, Hestrin-Schramm Mannitol, Molasses, Molasses Mannitol, High Fructose Corn Syrup, and High Fructose Corn Syrup Mannitol) and were autoclaved at 120 degrees Celsius for 20 minutes to ensure sterility. The sterile media were then inoculated with $125 \mathrm{ml}$ of the bacterial liquid each for a $10 \%$ inoculation by volume.

\section{Material nutrients}

Acetobacter xylinum \#10245 was obtained from the American Type Culture Collection (ATCC). Three media varieties were investigated: Hestrin-Schramm, Molasses, and High Fructose Corn Syrup; furthermore, each media had a subgroup brewed with the addition of mannitol for a total of six distinct varieties of media. Media ingredients were primarily supplied by Fisher Scientific. All media were made with deionized water in addition to their respective formula ingredients. Half of each media type had the addition of 40g/l of Mannitol (M) added. Materials for the Hestrin Schramm and Hestrin Schramm Mannitol (HS, HSM) media were based on the original formula published by Hestrin and Schramm in 1954 and included Glucose, Peptone, Yeast Extract, Disodium Phosphate and Citric Acid.

The molasses media (MS) included Treated Molasses (Supreme Baking Molasses, Golden Barrel) Supernatants [12]. The supernatants were 5 times distilled, with 1 part molasses and 4 parts deionized water. Then, they were centrifuged at a speed of 7200 rpm for 15 minutes. The supernatant was collected and adjusted to a pH of 3 . Then, the supernatant was centrifuged again. In addition to the treated molasses supernatants, the following ingredients were added based on the media from Jung HI, et al. [39]; Polypeptone, Yeast Extract, Sodium Dihydrogen and Phosphate Dodecahydrate. Half of these samples had $40 \mathrm{~g} / \mathrm{l}$ of Mannitol added to the media (MSM). Finally, the high fructose corn syrup media (HFCS) included High Fructose Corn Syrup (Brushy Mountain Bee Farm) supernatants treated in the same manner as the molasses described above. In addition to the treated supernatants, the following ingredients were added based on the media from Jung HI, et al. [39]; Polypeptone, Yeast Extract, Sodium Dihydrogen and Phosphate Dodecahydrate. Half of these samples had 40g/l of Mannitol added to the media (HFCSM).

\section{Incubation and material processing}

The growing containers were incubated at 30 degrees Celsius for 21 days. After the growth period, the cellulose was treated with a $1 \% \mathrm{NaOH}$ and deionized water solution to purify the cellulose. The mats were covered with the solution and left to soak at room temperature for 24 hours. These mats were then rinsed with deionized water until a neutral $\mathrm{pH}$ was reached. From this point, half of the samples were placed in a 96 hour, 10\% glycerol and distilled water solution. After the soak, the mats were rinsed again with distilled water to remove the glycerol from the surface. Half of all the samples were air dried at 72 degrees Fahrenheit and the remaining half were freeze dried at -32 to -42 degrees Fahrenheit. After drying, the samples were weighed to ensure moisture removal until the samples maintained a consistent weight for three days [40].

\section{Material property testing}

Presence of desirable attributes of the material for apparel was tested, including grams per litre yield, tensile strength, breaking elongation and abrasion resistance. Grams per litre were determined by weighing the samples after the drying procedure. After the samples recorded the same weight for 3 days, this weight was used to determine grams per litre of cellulose produced. The weighting down effect of the glycerol treatment was not controlled for in this experiment as this would have required drying the material before application of the treatment. Averages are reported from 1-5 pellicle samples per group. Abrasion resistance was tested according to ASTM 4966 with a Martindale abrasion tester, standard wool abradant, and a $9 \mathrm{kPa}$ weight. Cycles were run until a hole or tear appeared or 5000 cycles were reached. Tensile strength and breaking elongation were measured with ASTM 882, 100mm by $5 \mathrm{~mm}$ samples with a gauge length of 3 inches and a speed of $500 \mathrm{~mm}$ per minute.

\section{Results}

\section{Hestrin Schramm (HS)}

With the standard media in the air drying condition, an average output of .52 grams of cellulose per litre (SD $=.04$ ) was achieved. An average strength of 2.05 newton's (SD $=.97$ ) was noted with air dried HS samples. In terms of elongation, these strips had an average breaking extension of $4.65 \mathrm{~mm}$ ( $S D=2.32$ ). When testing abrasion resistance, the average cycles underwent by the material before a hole or tear appeared was 50 . Looking at this media with the freeze drying condition, an average output of .54 grams of cellulose per litre (SD = .04) was achieved. An average breaking strength of 2.12 Newton's (SD = 2.05) was achieved with an average breaking extension of $2.14 \mathrm{~mm}(\mathrm{SD}=1.04)$. Abrasion resistance in this condition registered 50 cycles before a hole or tear appeared.

The addition of the glycerol plasticizing treatment as a finishing technique caused some noticeable changes to the material. Air dried material from this media finished in this manner resulted in an average weight of 5.41 grams per litre of cellulose (SD $=2.21$ ). Average breaking strength became 5.03 newton's (SD = 4.25) with an average breaking extension of $9.28 \mathrm{~mm}(\mathrm{SD}=4.42$ ). Abrasion resistance was increased to an average of 100 cycles. Freeze dried HS material after the glycerol soak resulted in an average weight of 1.02 grams per litre of cellulose (SD $=.54$ ). This material posted an average of 7.61 newton's ( $S D=5.78$ ) for breaking strength and an average breaking extension of $2.88 \mathrm{~mm}(\mathrm{SD}=1.40)$. Abrasion resistance became 1200 cycles before a hole or tear appeared.

\section{Hestrin Schramm Mannitol (HSM)}

After the addition of mannitol to the standard media's BC in the air drying condition, an average output of .63 grams of cellulose per litre (SD = .27) was achieved. When testing tensile strength, an 
average strength of 2.49 newton's (SD $=1.19$ ) was noted. In terms of elongation, these strips had an average breaking elongation of $4.46 \mathrm{~mm}(\mathrm{SD}=2.10$ ). When testing abrasion resistance, the average cycles underwent by the material before a hole or tear appeared was 100 . With this media in the freeze drying condition, an average output of .70 grams of cellulose per litre (SD = .14) was achieved. An average breaking strength of 3.60 newton's (SD $=.94$ ) was noted with an average breaking elongation of $2.38 \mathrm{~mm}(\mathrm{SD}=.34$ ). Abrasion resistance in this condition reached 900 cycles before a hole or tear appeared.

The glycerol soak finishing technique caused some noticeable changes to the material grown in this media as well. Air dried material from this media finished in this manner resulted in an average weight of 7.54 grams per litre of cellulose (SD $=4.85$ ). Average breaking strength became 15.18 newton's (SD $=11.33$ ) with an average breaking extension of $8.63 \mathrm{~mm}(\mathrm{SD}=3.48)$. Abrasion resistance increased to an average of 300 cycles. Freeze dried HSM material after the glycerol soak produced 1.61 grams of cellulose ( $S D=.19)$. This material reached an average of 13.78 newton's (SD $=4.45$ ) for breaking strength and an average breaking extension of $11.56 \mathrm{~mm}$ (SD $=4.43$ ). Abrasion resistance became 1500 cycles before a hole or tear appeared.

\section{High Fructose Corn Syrup (HFCS)}

With the first cost-effective media option, high fructose corn syrup was used as a replacement for laboratory grade glucose utilizing high fructose corn syrup as a substitute. This material produced noticeable differences to the material grown with Hestrin Schramm media. In the air drying condition for this media, an average output of .74 grams of cellulose per litre (SD $=.06$ ) was achieved. Breaking strength averaged .46 newton's (SD = .55) with $3.64 \mathrm{~mm}(\mathrm{SD}=4.44)$ as the average breaking extension. The average number of abrading cycles endured by the material before a hole or tear appeared increased from the HS air dried material to an average of 200 for the HFCS produced material. Looking at this media in the freeze drying condition, an average output of .63 grams of cellulose per litre (SD = .04) was achieved. 1.73 newton's (SD = 1.61) was achieved for average breaking strength with $1.19 \mathrm{~mm}(\mathrm{SD}=.62)$ as the average breaking extension. The material was able to undergo 100 cycles in the abrasion tester before a hole or tear appeared.

The glycerol soak continued the finish's plasticizing effect on the material. Air dried material from the media subjected to the finishing soak averaged 4.49 grams per litre of cellulose (SD = 1.14). Average breaking strength from this condition reached 6.40 Newton (SD = 1.31), with an average breaking extension of $6.31 \mathrm{~mm}$ (SD $=.94)$. Abrasion resistance was increased to an average of 300 cycles in comparison to the non-finished HFCS air dried material. Freeze dried and treated HFCS material generated 3.43 grams per litre of cellulose $(\mathrm{SD}=.73)$. This material achieved an average of 7.25 newton's (SD $=.10$ ) for breaking strength and $6.87 \mathrm{~mm}$ (SD $=.91$ ) for breaking elongation. Abrasion resistance remained an average of 100 cycles in comparison to the non-finished HFCS freeze dried material.

\section{High Fructose Corn Syrup Mannitol (HFCSM)}

The addition of mannitol to the media was made in an effort to boost cellulose yield and enhance understanding of the effects of mannitol on the resulting cellulose. In the air drying condition for this media, an average output of 89 grams of cellulose per litre (SD = 0.19 ) was achieved, which was higher than the air drying condition of the HFCS media. Breaking strength averaged .58 newton's (SD = 1.35) with an average breaking elongation of $5.07 \mathrm{~mm}(\mathrm{SD}=7.37)$. The average number of abrading cycles endured by the material before a hole or tear appeared increased from the HSM air dried material to an average of 700 for the HFCSM produced material. Looking at this media in the freeze drying condition, the average grams per litre of cellulose yield was .56 ( $\mathrm{SD}=0.00)$, which was less than the yield of the freeze dried HFCS. 1.48 Newton's (SD = 1.33) was the average breaking strength with $1.28 \mathrm{~mm}(\mathrm{SD}=.63)$ as the average breaking extension. The material was able to undergo 100 cycles in the abrasion tester before a hole or tear appeared.

The glycerol soak produced marked changes to the material in the HFCSM condition. Air dried material from the media subjected to the finishing soak averaged 4.67 grams per litre of cellulose (SD = 1.89). This output was slightly higher than the air dried and finished material in the HFCS condition. Average breaking strength from this condition reached 5.97 Newton (SD $=1.67$ ), with an average breaking extension of $8.91 \mathrm{~mm}(\mathrm{SD}=3.54)$. Abrasion resistance was reduced to an average of 100 cycles in comparison to the nonfinished HFCS air dried material. Freeze dried and treated HFCSM material produced an average of 3.35 grams of cellulose per litre (SD = 1.51). This material achieved an average of 9.77 newton's (SD $=5.48$ ) for breaking strength and $9.37 \mathrm{~mm}(\mathrm{SD}=3.40)$ for breaking extension. Abrasion resistance was increased to an average of 600 cycles in comparison to the treated HFCS freeze dried material.

\section{Molasses (MS)}

In the second economically geared media, treated molasses supernatant was used as a replacement laboratory grade glucose. This material produced noticeable differences to the material grown with Hestrin Schramm media as well. In the air drying condition for this media, an average yield of .85 grams of cellulose per litre (SD = .06) was noted, higher than either of the other two main types of media's untreated material (HS \& HFCS). Average breaking strength was 1.92 newton's (SD = 1.57) with an average breaking extension of $1.77 \mathrm{~mm}(\mathrm{SD}=.67)$. The average number of abrading cycles underwent by the material before a hole or tear appeared increased from the HS air dried material to an average of 300 for the MS produced material. In the freeze drying condition, an average output of .67 grams of cellulose per litre (SD = .04) was achieved. This slightly outperformed the other two main types of media's untreated material in the freeze drying condition. 2.30 newton's (SD = 2.11) was achieved for average breaking strength 
with $1.76 \mathrm{~mm}(\mathrm{SD}=.51)$ as the average breaking extension. The material was able to undergo 100 cycles in the abrasion tester before a hole or tear appeared.

Air dried material from the media subjected to the finishing soak averaged 4.19 grams per litre of cellulose ( $S D=1.28$ ). This output was somewhat lower than the air dried and finished material in both other Medias. Average breaking strength from this condition reached 3.46 Newton (SD = 1.17), with an average breaking extension of $4.28 \mathrm{~mm}(\mathrm{SD}=.97)$. Abrasion resistance was reached an average of 250 cycles in comparison to the treated HS and HFCS air dried material. Freeze dried and treated MS material had an average output of 2.11 grams per litre (SD $=.57$ ). This material achieved an average of 5.10 newton's (SD $=3.79$ ) for breaking strength and $7.05 \mathrm{~mm}(\mathrm{SD}=4.08)$ for breaking extension. Abrasion resistance reached an average of 100 cycles.

\section{Molasses Mannitol (MSM)}

In the air drying condition for the molasses mannitol media, an average output of 4.80 grams of cellulose per litre (SD $=2.34$ ) was achieved, which was much higher than the air drying condition of the MS media. Breaking strength averaged 14.17 newton's (SD = 11.01 ) with an average breaking extension of $2.89 \mathrm{~mm}$ (SD $=1.79$ ). The average number of abrading cycles the material experienced

Table 1: Results of non-treated media. increased from the HSM \& HFCSM air dried materials to an average of 5000 without producing a hole or tear for the MSM produced material. In the freeze drying condition, the average grams per litre of cellulose yield was 7.78, which was greater than the yield of the freeze dried MS. 38.26 newton's (SD = 21.43) was the average breaking strength with $6.48 \mathrm{~mm}(\mathrm{SD}=2.71)$ as the average breaking extension. The material was able to undergo 5000 cycles in the abrasion tester without a hole or tear appearing.

The glycerol soak produced substantive changes to the material in the MSM condition. Air dried material from the media subjected to the finishing soak averaged 19.98 grams per litre of cellulose (SD =6.61). This output was quite higher than the air dried and finished material in the MS condition. Average breaking strength from this condition reached 7.69 Newton (SD $=4.90$ ), with an average breaking extension of $11.06 \mathrm{~mm}(\mathrm{SD}=2.61)$. Abrasion resistance was reduced to an average of 900 cycles in comparison to the non-finished MSM air dried material. Freeze dried and treated MSM material generated 12.63 grams per litre of cellulose $(\mathrm{SD}=$ 4.76). This material achieved an average of 11.75 newton's (SD = 6.56) for breaking strength and $11.61 \mathrm{~mm}(\mathrm{SD}=4.10$ ) for breaking elongation. Abrasion resistance was reduced to an average of 700 cycles in comparison to the non-finished MSM freeze dried material (Tables 1\&2).

\begin{tabular}{|c|c|c|c|c|c|c|c|c|c|c|c|c|}
\hline \multirow{2}{*}{ Media } & \multicolumn{2}{|c|}{ HS } & \multicolumn{2}{|c|}{ HSM } & \multicolumn{2}{|c|}{ HFCS } & \multicolumn{2}{|c|}{ HFCSM } & \multicolumn{2}{|c|}{ MS } & \multicolumn{2}{|c|}{ MSM } \\
\hline & Air & Freeze & Air & Freeze & Air & Freeze & Air & Freeze & Air & Freeze & Air & Freeze \\
\hline Average g/l & 0.52 & 0.54 & 0.63 & 0.7 & 0.74 & 0.63 & 0.89 & 0.56 & 0.85 & 0.67 & 4.8 & 7.78 \\
\hline $\begin{array}{l}\text { Average Breaking } \\
\text { Strength }(\mathrm{N})\end{array}$ & 2.05 & 2.12 & 2.49 & 3.6 & 0.46 & 1.73 & 0.58 & 1.48 & 1.92 & 2.3 & 14.17 & 38.26 \\
\hline $\begin{array}{l}\text { Average Breaking } \\
\text { Extension }(\mathrm{mm})\end{array}$ & 4.65 & 2.14 & 4.46 & 2.38 & 3.64 & 1.19 & 5.07 & 1.28 & 1.77 & 1.76 & 2.89 & 6.48 \\
\hline $\begin{array}{l}\text { Average Abrading } \\
\text { Cycles }\end{array}$ & 50 & 50 & 100 & 900 & 200 & 100 & 700 & 100 & 300 & 100 & 5000 & 5000 \\
\hline
\end{tabular}

Table 2: Results of glycerol treated media.

\begin{tabular}{|c|c|c|c|c|c|c|c|c|c|c|c|c|}
\hline \multirow{2}{*}{ Media } & \multicolumn{2}{|c|}{ HS } & \multicolumn{2}{|c|}{ HSM } & \multicolumn{2}{|c|}{ HFCS } & \multicolumn{2}{|c|}{ HFCSM } & \multicolumn{2}{|c|}{ MS } & \multicolumn{2}{|c|}{ MSM } \\
\hline & Air & Freeze & Air & Freeze & Air & Freeze & Air & Freeze & Air & Freeze & Air & Freeze \\
\hline Average g/l & 0 & 0 & 7.54 & 1.61 & 4.49 & 3.43 & 4.67 & 3.35 & 4.19 & 2.11 & 19.98 & 12.63 \\
\hline $\begin{array}{c}\text { Average Breaking } \\
\text { Strength }(\mathrm{N})\end{array}$ & 5.03 & 7.61 & 15.18 & 13.78 & 6.4 & 7.25 & 5.97 & 9.77 & 3.46 & 5.1 & 7.69 & 11.75 \\
\hline $\begin{array}{c}\text { Average Breaking } \\
\text { Extension }(\mathrm{mm})\end{array}$ & 9.28 & 2.88 & 8.63 & 11.56 & 6.31 & 6.87 & 8.91 & 9.37 & 4.28 & 7.05 & 11.06 & 11.61 \\
\hline $\begin{array}{l}\text { Average Abrading } \\
\text { Cycles }\end{array}$ & 100 & 200 & 300 & 1500 & 300 & 100 & 100 & 600 & 250 & 100 & 900 & 700 \\
\hline
\end{tabular}

The addition of mannitol to each media type played an important role in the yield of cellulose, increasing this yield across all conditions. This is most clearly illustrated in the Molasses Mannitol (MSM) samples as the full pellicle weight was four or more times higher in these samples. Comparing the three media types, the addition of mannitol increased breaking strength performance across all media except for HFCSM treated, freeze dried samples. Breaking elongation benefited from the addition of the mannitol as well, with all but 3 of the groups showing an increase in breaking extension. Abrasion resistance for all but 1 group also improved with the addition of mannitol.

The effects of glycerol on the samples were dependent on the media used. For average grams of cellulose per litre produced the treated glycerol samples had a higher g/l yield, likely due to its hydrating effects, which keep BC in more of its hydrogel state. The glycerol treatment also increased the average breaking strength and breaking elongation amongst most media, except for a decrease 
in breaking strength for MSM both air and freeze dried. The effects of glycerol on abrasion resistance showed an increase for HS (air and freeze dried), HSM (air and freeze dried), HFCS (air dried), and HFCSM (freeze dried); whereas, HFCS (freeze dried) remained the same, HFCSM (air dried) decreased, MS (air dried) decreased, MS (freeze dried) remained the same, and MSM (air and freeze dried) decreased drastically.

The glycerol treatment most positively impacted the breaking extension of the material tested, increasing the amount the material could be extended before rupture in all media and drying conditions in comparison to the non-treated material. The glycerol treatment also added weight to the material, changing the nature of the material's drape (Figure 1). Most BC varieties were not able to withstand 5000 abrading cycles without a hole or tear appearing in the material, indicating more progress will need to be made in material modification before it will be able to be used in apparel.

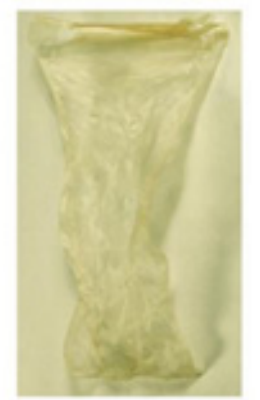

HFCS Air

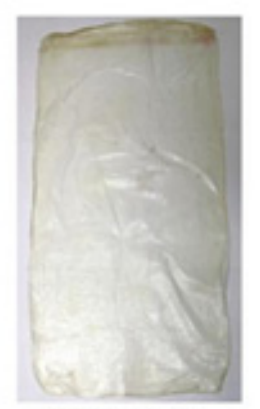

HFCS Gly Air

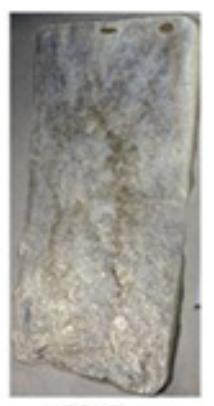

HFCS Freeze

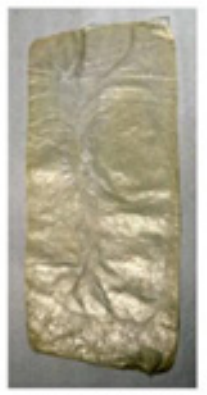

HFCS Gly Freeze

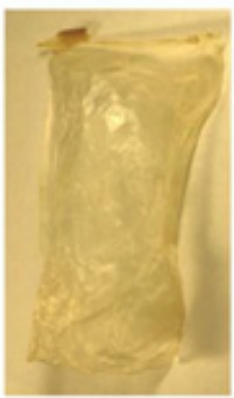

HFCSM Air

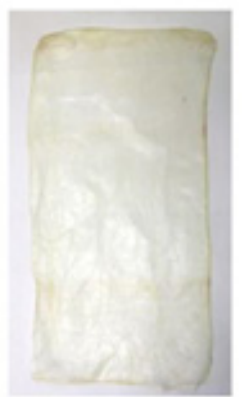

HFCSM Gly Air

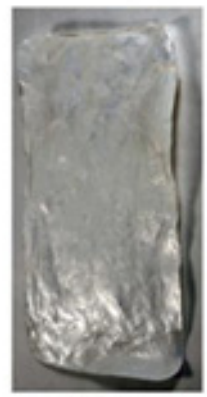

HFCSM Freeze

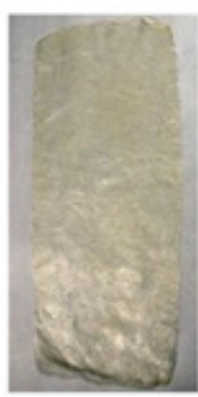

HFCSM Gly Freeze

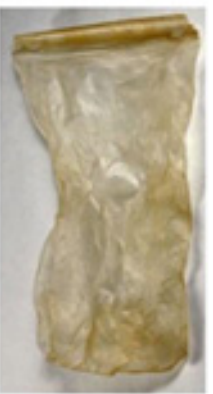

MS Air

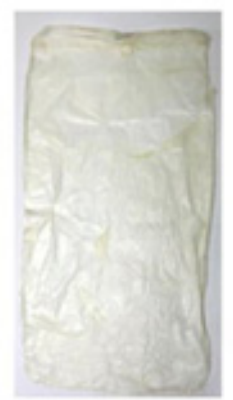

MS Gly Air

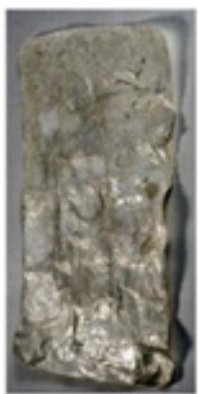

MS Freeze

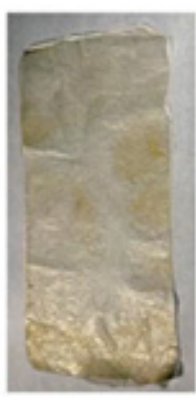

MS Gly Freeze

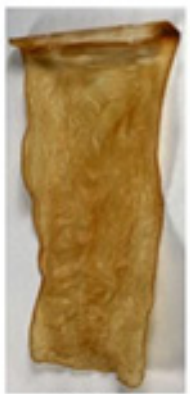

MSM Air

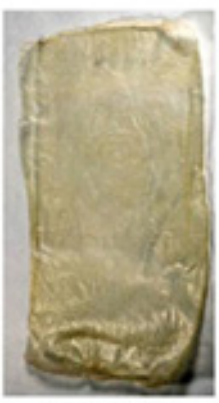

MSM Gly Air

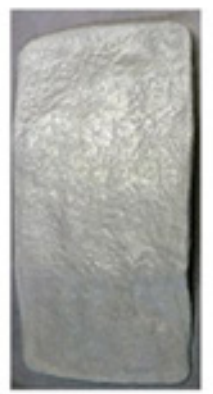

MSM Freeze

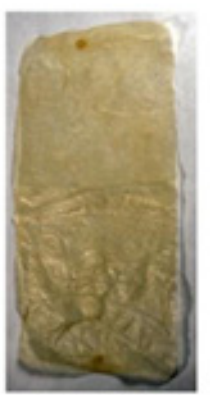

MSM Gly Freeze

Figure 1: Photos of the BC Pellicles. 
Overall, MSM media, both none and treated glycerol samples, had the highest $\mathrm{g} / \mathrm{l}$ of cellulose produced. As for average breaking strengths MSM non treated glycerol samples had the highest results and non-treated HFCS, on average had the weakest breaking strengths. MSM treated samples produced the highest average breaking elongation and MS media produced the lowest elongation. Interestingly, MSM media had the highest abrasion resistance and results identify HS media as the lowest. From these results it can be deduced that MSM media provided the most cellulose and stronger samples.

\section{Conclusion}

Cultivation of traditional laboratory grade bacterial cellulose is time consuming and costly. Pure media component costs coupled with the time necessary to incubate the materials likely means that bacterial cellulose will continue to be used for high value products. Low cost glucose substitutes in this study showed promise, but still needed pure mannitol to yield significant amounts of cellulose. Potential exists for the material as an alternative to leather, but significant advances will need to be made for BC to challenge traditional cellulosic fibres, like cotton.

\section{Acknowledgement}

The primary author would like to thank the University of Wyoming Faculty Grant-in-Aid program for the funding which made this research possible.

\section{Conflicts of Interest}

There are no conflicts of interest to report.

\section{References}

1. Claudio L (2007) Waste couture: Environmental impact of the clothing industry. Environmental Health Perspectives 115(9): A449.

2. Rosenau JA, Wilson DL (2014) Apparel merchandising: The line starts here. Fairchild Books, New York, USA.

3. Environmental Protection Agency (EPA) (2014) Textiles: MaterialSpecific data.

4. Kasemset C, Chernsupornchai J, Pala-ud W (2015) Application of MFCA in waste reduction: case study on a small textile factory in Thailand. Journal of Cleaner Production 108: 1342-1351.

5. Esa F, Tasirin SM, Rahman NA (2014) Overview of bacterial cellulose production and application. Agriculture and Agricultural Science Procedia 2(1): 113-119.

6. Yang G, Xie, J, Deng Y, Bian Y, Hong F (2012) Hydrothermal synthesis of bacterial cellulose/AgNPs composite: a "green" route for antibacterial application. Carbohydrate Polymers 87(4): 2482-2487.

7. National Cotton Council of America (2013) Which country grows the most cotton?

8. Kadolph SJ (2007) Textiles: (10 ${ }^{\text {th }}$ Edn). Upper Saddle River, NJ: Pearson Education, USA.

9. Kadolph SJ, Marcketti SB (2016) Textiles: (12 ${ }^{\text {th }}$ Edn). Upper Saddle River, NJ: Pearson Education, USA.

10. Dahman Y, Jayasuriya KE, Kalis M (2010) Potential of biocellulose nanofibers production from agricultural renewable resources: preliminary study. Appl Biochem Biotechnol 162(6): 1647-1659.
11. Chan CK, Shin J, Jiang SX (2018) Development of tailor-shaped bacterial cellulose textile cultivation techniques for zero-waste design. Clothing and Textiles Research Journal 36(1): 33-44.

12. Li L, Frey M, Browning KJ (2010) Biodegradability study on cotton and polyester fabrics. Journal of Engineered Fibers and Fabrics 5(4): 42-53.

13. Textile World (2013) Finland to lead the way as a designer of cellulosebased products.

14. Ashori A Sheykhnazari S, Tabarsa T, Shakeri A, Golalipour M (2012) Bacterial cellulose/silica nanocomposites: Preparation and characterization. Carbohydrate Polymers 90(1): 413-418.

15. Brown RM (1998) Microbial cellulose: a new resource for wood, paper, textiles, food and specialty products. Position Paper.

16. Brown Jr RM (2004) Cellulose structure and biosynthesis: what is in store for the $21^{\text {st }}$ century? Journal of Polymer Science Part A: Polymer Chemistry 42(3): 487-495.

17. Cai Z, Kim J (2010) Bacterial cellulose/poly (ethylene glycol) composite: characterization and first evaluation of biocompatibility. Cellulose 17(1): 83-91.

18. Hsieh YC, Yano H, Nogi M, Eichhorn SJ (2008) An estimation of the Young's modulus of bacterial cellulose filaments. Cellulose 15(4): 507513.

19. Khattak WA, Khan T, Ul-Islam M, Wahid F, Park JK (2015) Production, characterization and physico-mechanical properties of bacterial cellulose from industrial wastes. Journal of Polymers and the Environment 23(1): 45-53.

20. Environmental Protection Agency EPA (2019) Advancing Sustainable Materials Management: Facts and Figures, Sustainable Materials Management.

21. Iguchi M, Yamanaka S, Budhiono A (2000) Bacterial cellulose-a masterpiece of nature's arts. Journal of Materials Science 35(2):261-270.

22. Textile World (2013) Finland to lead the way as a designer of cellulosebased products.

23. Moon RJ, Martini A, Nairn J, Simonsen J, Youngblood J (2011) Cellulose nanomaterials review: structure, properties and nanocomposites. Chemical Society Reviews 40(7): 3941-3994.

24. Ferguson A, Khan U, Walsh M, Lee KY, Bismarck A, et al. (2016) Understanding the dispersion and assembly of bacterial cellulose in organic solvents. Biomacromolecules 17(5): 1845-1853.

25. Augimeri RV, Strap JL (2015) The Phytohormone Ethylene Enhances Cellulose Production, Regulates CRP/FNRKx Transcription and Causes Differential Gene Expression within the Bacterial Cellulose Synthesis Operon of Komagataeibacter (Gluconacetobacter) xylinus ATCC 53582. Front Microbiol 6: 1459.

26. Campano C, Balea A, Blanco A, Negro C (2016) Enhancement of the fermentation process and properties of bacterial cellulose: a review. Cellulose 23(1): 57-91.

27. Masaoka SR, Ohe T, Sakota N (1993) Production of cellulose from glucose by Acetobacterxylinum. Journal of Fermentation and Bioengineering 75(1): 18-22.

28. El-Saied H, Basta AH, Gobran RH (2004) Research progress in friendly environmental technology for the production of cellulose products (bacterial cellulose and its application). Polymer-Plastics Technology and Engineering 43(3): 797-820.

29. Lapuz MM, Gallardo EG, Palo MA (1967) The nata organism cultural requirements characteristics and identity coconut $\mathrm{m}$ Acetobacterxylinum. Philippine Journal of Science 96(2): 91-109.

30. Hestrin S, Schramm M (1954) Synthesis of cellulose by Acetobacterxylinum. II. Preparation of freeze-dried cells capable of polymerizing glucose to cellulose. Biochem J 58(2): 345-352.

31. Ruka DR, Simon GP, Dean KM (2012) Altering the growth conditions of Gluconacetobacter xylinus to maximize the yield of bacterial cellulose. Carbohydrate Polymers 89(2): 613-622. 
32. Gadag RV, Shetty AN (2010) Engineering Chemistry. International Pub. House Pvt. Ltd, New Delhi, India.

33. Kongruang S (2008) Bacterial cellulose production by Acetobacterxylinum strains from agricultural waste products. Appl Biochem Biotechnol 148(1-3): 245-256.

34. Bae S, Sugano Y, Shoda M (2004) Improvement of bacterial cellulose production by addition of agar in a jar fermentor. Journal of Bioscience and Bioengineering 97(1): 33-38.

35. Tanpichai S, Quero F, Nogi M, Yano H, Young RJ, et al. (2012) Effective Young's modulus of bacterial and micro fibrillated cellulose fibrils in fibrous networks. Biomacromolecules 13(5): 1340-1349.

36. Miguel R, Lucas J, Carvalho L, Santos Silva M, Manich A (2007) Garment abrasion strength evaluation: A comparative methods study. International Journal of Clothing Science and Technology 19(3/4): 194203.
37. Illa MP, Sharma CS, Khandelwal M (2019) Tuning the physiochemical properties of bacterial cellulose: effect of drying conditions. Journal of Materials Science 54(18): 12024-12035.

38. Zeng M, Laromaine A, Roig A (2014) Bacterial cellulose films: influence of bacterial strain and drying route on film properties. Cellulose 21: 4455-4469.

39. Jung HI, Lee OM, Jeong JH, Jeon YD, Park KH, et al. (2010) Production and characterization of cellulose by Acetobacter sp. V6 using a cost-effective molasses-corn steep liquor medium. Appl Biochem Biotechnol 162(2): 486-497.

40. Chen G, Wang W (2007) Role of freeze drying in nanotechnology. Drying Technology 25(1): 29-35. 